"Improved Vehicle-to-Home (iV2H) Operation Mode: Experimental Analysis of the Electric Vehicle as Off-Line UPS"

IEEE Transactions on Smart Grid, 2017.

http://ieeexplore.ieee.org/document/7432043/

ISSN: 1949-3053

DOI 10.1109/TSG.2016.2535337

This material is posted here with permission of the IEEE. Such permission of the IEEE does not in any way imply IEEE endorsement of any of Group of Energy and Power Electronics, University of Minho, products or services. Internal or personal use of this material is permitted. However, permission to reprint/republish this material for advertising or promotional purposes or for creating new collective works for resale or redistribution must be obtained from the IEEE by writing to pubs-permissions@ieee.org. By choosing to view this document, you agree to all provisions of the copyright laws protecting it. 


\title{
Improved Vehicle-to-Home (iV2H) Operation Mode: Experimental Analysis of the Electric Vehicle as Off-Line UPS
}

\author{
Vítor Monteiro, Student Member, IEEE, Bruno Exposto, Student Member, IEEE, \\ João C. Ferreira, Member, IEEE, João L. Afonso, Member, IEEE
}

\begin{abstract}
This paper presents experimental results of the electric vehicle (EV) operation as an off-line uninterruptible power supply (UPS). Besides the traditional grid-to-vehicle (G2V) and vehicle-to-grid (V2G) modes, this paper presents an improved vehicle-to-home (iV2H) operation mode. This new operation mode consists in the detection of a power outage in the power grid and the change of the EV battery charger control to operate as an off-line UPS. When the power grid voltage is restored, the voltage produced by the on-board EV battery charger is slowly synchronized with the power grid voltage before a complete transition to the normal mode. This paper presents results of two algorithms to detect a power outage: the rms calculation method based on half-cycle of the power grid voltage, and the rms estimation based on a Kalman filter. The experimental results were obtained in steady and transient state considering two cases with the EV plugged in at home: when charging the batteries, and without charging the batteries. The paper describes the EV battery charger, the power outage detection methods and the voltage and current control strategies.
\end{abstract}

Index Terms-Electric vehicle, Kalman filter, improved vehicle-to-home (iV2H), Off-line UPS.

\section{INTRODUCTION}

$\mathrm{T}$ HE electric vehicle (EV) has attracted the attention of the transports sector, mainly due to environmental concerns and restrictions on energy resources [1][2]. In this context, with the EV introduction in the power grids, several opportunities emerge, and this represents a step forward to the users and to the smart grids [3][4][5]. For instance, a coordinated EV battery charging to minimize power quality problems is presented in [6], the EV integration considering the energy management for homes is presented in [7], and considering the power grid technical operation and the markets is presented in [8]. The EV integration combined with renewable energy systems for reducing emission is presented in [9] and an optimization of the power grid is presented in [10]. Concerning the power quality, the $\mathrm{EV}$ can be used to compensate current harmonic distortion, to exchange active power through the grid-to-vehicle $(\mathrm{G} 2 \mathrm{~V})$ and vehicle-to-grid

This work has been supported by FCT - Fundação para a Ciência e Tecnologia in the scope of the projects: PEst-UID/CEC/00319/2013.

Vítor Monteiro, Bruno Exposto, João C. Ferreira, and João L. Afonso are with Centro Algoritmi, University of Minho, Dept. Industrial Electronics, 4800-058 Guimarães, Portugal; emails: vmonteiro@dei.uminho.pt, bexposto@dei.uminho.pt,jferreira@deetc.isel.ipl.pt, and jla@dei.uminho.pt.
(V2G) operation modes [11], and to inject reactive power to the power grid [12][13]

Besides the G2V and V2G modes, the EV operation as a power source, when disconnected from the power grid, is presented in [14]. Similarly, the EV operation as a battery storage and as a backup generator in homes is presented in [15]. This concept, denominated vehicle-to-home (V2H), can be used to feed any electrical appliance in the place where the EV is parked. However, it does not have the capability to operate as an off-line uninterruptible power supply (UPS). To overcome this drawback, the operation of the EV battery charger as off-line UPS was initially proposed by the authors in [16]. However, preliminary results have been validated only with linear electrical appliances, which is not a realistic condition. It is important to highlight that the terminology V2H can also aggregate the G2V and V2G when the EV plugged in at home [17]. However, in such case, the EV cannot operate as a backup power source, i.e., as an off-line UPS.

In the scope of this paper, the initial $\mathrm{V} 2 \mathrm{H}$ operation mode was improved in order to allow a faster detection of a power outage and consequently a reduced transference time. Also, this new mode can operate with nonlinear electrical appliances. Therefore, it is denominated improved vehicle-to-home (iV2H) operation mode. This iV2H operation mode is specially dedicated to smart homes in order to provide energy to the electrical appliances during power outages, contributing to improve the reliability and the security of the power grid against failures (e.g., when major natural phenomena occur). Fig. 1 shows this concept framed with the G2V and V2G

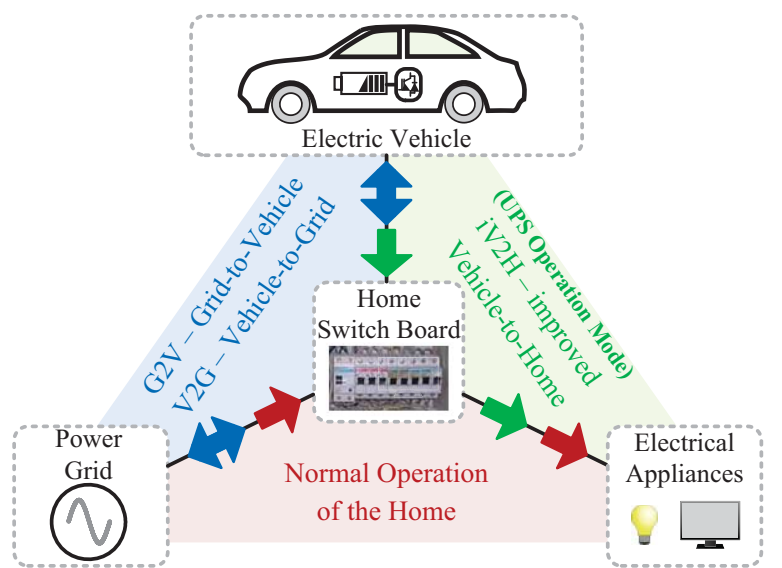

Fig. 1. Electric vehicle operation modes: Grid-to-Vehicle (G2V); Vehicle-to-Grid (V2G); improved Vehicle-to-Home (iV2H). 


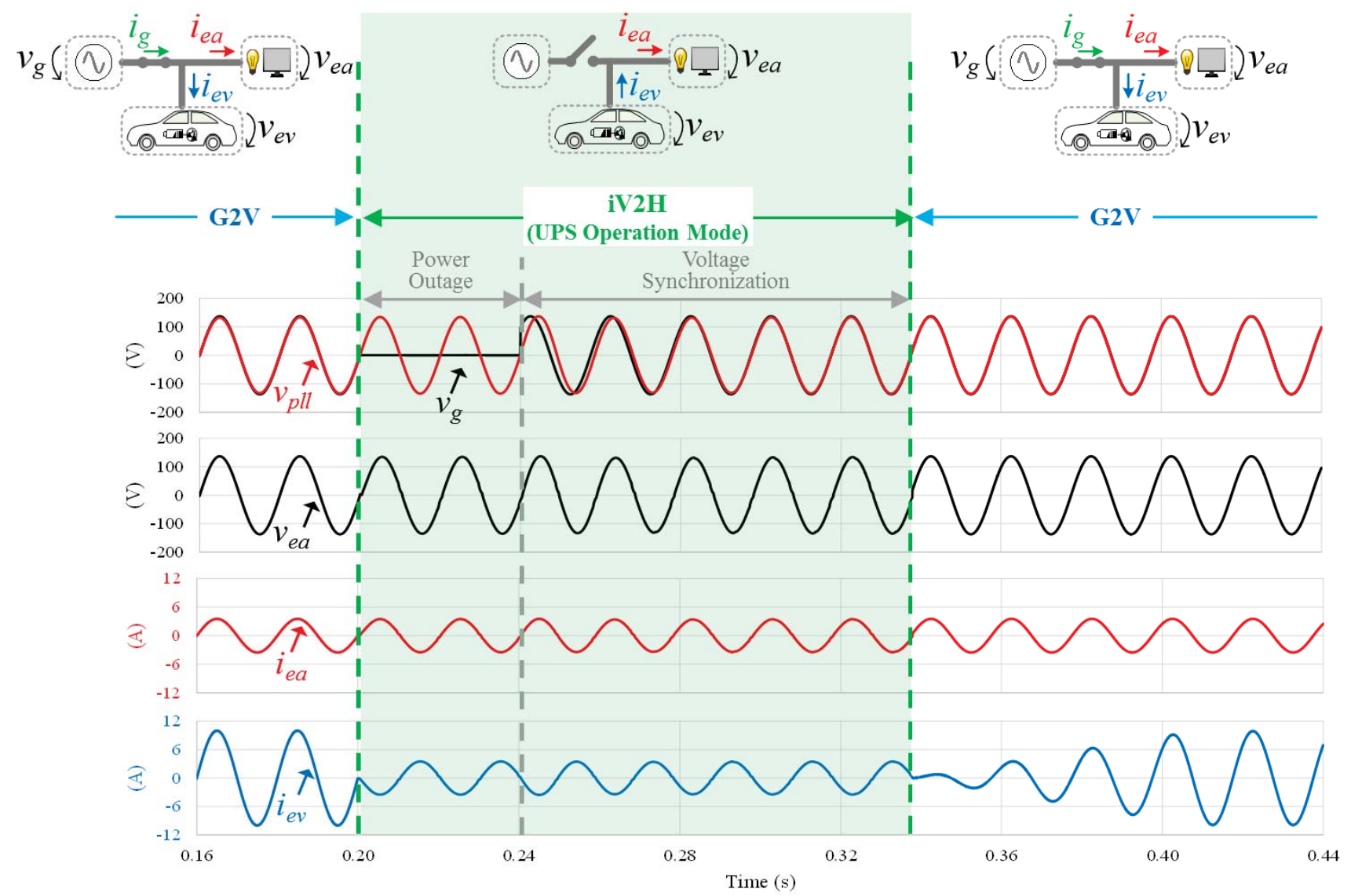

Fig. 2. Principle of operation of the proposed on-board bidirectional EV battery charger through the G2V and iV2H operation modes.

operation modes and the normal operation of the home.

The main purpose associated with the iV2H operation mode is to show that the EV can represent an asset to smart grids and smart homes besides the traditional approaches. These approaches include the role of the EV in smart homes as an energy storage system [18], its flexible integration to manage the smart home energy consumption [19] and user comfort [20], and an optimal centralized scheduling to combine its integration with the home electrical appliances consumption [21]. Nissan already proposed the utilization of the EV with smart homes through the "LEAF to Home" system [22]. Also Mitsubishi and Toyota have similar systems [23]. However, using these systems, the EV cannot operate as an off-line UPS.

In this sequence, the main contributions of this paper are: the experimental validation of the proposed $\mathrm{iV} 2 \mathrm{H}$ operation mode (EV as an off-line UPS) using an EV battery charger framed in a smart home with nonlinear electrical appliances (i.e., currents with harmonic distortion); the comparison of two digital control algorithms for EV battery chargers towards to detect power outages; the $\mathrm{iV} 2 \mathrm{H}$ operation mode for EV battery chargers with a Kalman filter considering nonlinear electrical appliances; an on-board EV battery charger capable of performing a fast transition (low transfer time) from the G2V (charging the batteries) to the iV2H operation mode (operation as an off-line UPS) and vice-versa (i.e., capable of performing a smooth synchronization with the power grid voltage).

The $\mathrm{iV} 2 \mathrm{H}$ operation mode is described in detail along the paper, where a special emphasis is given to the main contribution of the paper, i.e., the usage of an EV battery charger for the detection of power outages, to the operation as an off-line UPS, and to synchronization strategies when the power grid voltage is restored. The iV2H operation mode was validated through simulation and experimental results both in steady and transient state when the power outage occurs and for two cases: when the EV is plugged in at home but not charging the batteries, and when it is plugged in and charging the batteries.

The paper is organized as follows: after the introduction, section II presents a comparison of two digital control algorithms to detect power grid outages. The experimental results of the EV battery charger during the power outages and during the synchronization with the power grid voltage are presented in section III. Section IV presents the digital control algorithms for the EV battery charger during the G2V, V2G, and $\mathrm{iV} 2 \mathrm{H}$ operation modes. Section $\mathrm{V}$ presents the experimental results both in steady and transient state that validate the iV2H operation mode. Finally, section VI presents the main conclusions that illustrate the benefits of the iV2H operation mode (operation of the EV as an off-line UPS) as an emerging technology for smart homes and smart grids.

\section{II. iV2H OPERATION MODE}

Fig. 2 shows a typical principle of operation of the on-board EV battery charger through the G2V and iV2H operation modes, where, $v_{g}$ denotes the power grid voltage, $v_{p l l}$ indicates the PLL output signal, $v_{e a}$ implies the voltage applied to the electrical appliances, $i_{e a}$ means the current in electrical appliances, and $i_{e v}$ refers to the EV current. This figure was obtained through computer simulations using the simulation 
tool PSIM v9.0. As it can be seen, in a first stage the on-board EV battery charger is controlled to operate in the G2V operation mode. In a second stage, when a power outage occurs, the on-board EV battery charger changes the control algorithm to the iV2H operation mode. When the power grid voltage is restored, the PLL output signal is resynchronized with the power grid voltage and consequently the $v_{e a}$ is resynchronized with the grid voltage. When this resynchronization is complete, the on-board EV battery charger returns to the G2V operation mode (current control mode). The flowchart that illustrates the complete EV battery charger control algorithm behavior is shown in Fig. 3.

Nowadays, considering the trade-off cost/benefits, in most of the countries, it is not viable to install an UPS in each home. Therefore, the proposed $\mathrm{iV} 2 \mathrm{H}$ operation mode is an interesting solution without introducing extra costs or the change of the EV battery charger hardware. Moreover, this operation mode is more relevant considering that the EVs are parked at home between 9 p.m. and 6 a.m. and using a standard single-phase $230 \mathrm{~V}$ outlet [24]. It is important to note that this period, as well as the charging power, may vary according to the different charging levels (SAE) and modes (IEC 62196). In part, this period coincides with the largest energy consumption at home. It is also important to note that the EV represents an asset for power grid, because it can operate as a versatile active element, capable of consuming, storing, and providing energy. However, the EV with the iV2H operation mode (an off-line UPS) is to support the smart home according to the user's needs, i.e., it is not used to support the power grid. Using the iV2H operation mode, energy from the EV batteries is used. Therefore, this operation mode is not suitable for long periods of time, i.e., it should be used only during power outages. Moreover, the maximum amount of energy removed from the EV battery can be defined by the EV driver, and the total power of the electrical appliances cannot exceed the nominal power of the on-board EV battery charger $(3.5 \mathrm{~kW})$.

\section{A. Grid Voltage rms Calculation Method}

The most common method to detect power outages is based on the calculation of the voltage rms value and the assumption that when this value is lower than a predefined threshold, a power outage occurs. The simplest way to perform this task consists in using (1) to calculate the rms value:

$$
V_{G}(t)=\sqrt{\frac{1}{T} \int_{0}^{T} v_{g}(t)^{2} d t},
$$

where, $v_{g}(t)$ represents the instantaneous value of the power grid voltage and $V_{G}(t)$ means the rms value during the period $(T)$. However, to speed up the calculation, the rms value can be calculated only in a half-cycle and using a sliding window average of the rms values. The digital implementation of the sliding average for the instant $k$ is obtained using (2) and (3).

$$
\begin{gathered}
V_{G}{ }^{2}[k]=V_{G}{ }^{2}[k-1]-v_{g}{ }^{2}[k-N]+v_{g}{ }^{2}[k] . \\
V_{G}[k]=\sqrt{f_{S} \frac{V_{G}{ }^{2}[k]}{2 f}},
\end{gathered}
$$

where, $V_{G}^{2}[k]$ is the average of the square value of the power grid voltage, $N$ is the number of samples used in each cycle of the power grid voltage, $f_{s}$ denotes the sampling frequency, and $f$ indicates the fundamental frequency of the power grid voltage.

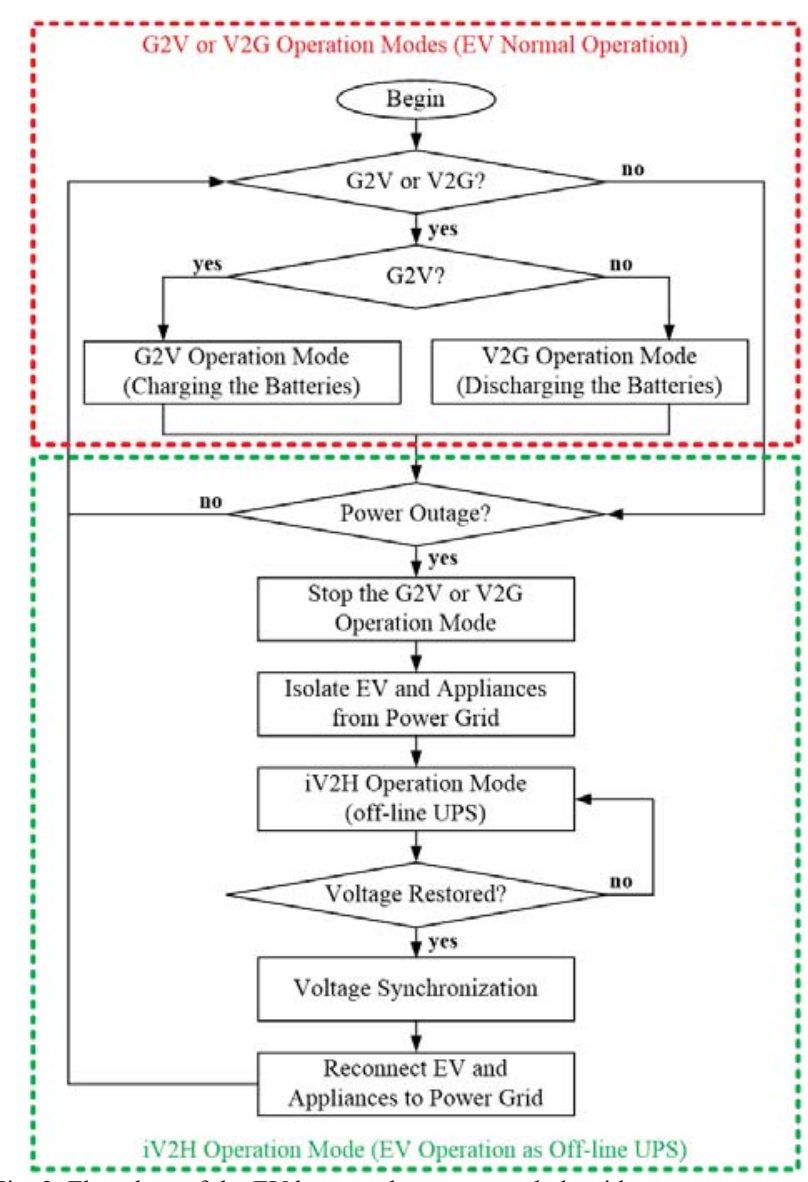

Fig. 3. Flowchart of the EV battery charger control algorithm.

\section{B. Grid Voltage rms Estimation Method}

As an alternative to the aforementioned method, a Kalman filter can be used to estimate the rms value of the power grid voltage [25]. This strategy consists in estimating the instantaneous amplitude of the fundamental power grid voltage $(s[k])$ and its quadrature signal $(q[k])$. These values are estimated using the following state estimation model:

$$
\hat{x}[k]=\mathrm{A} \hat{x}[\mathrm{k}-1],
$$

where, $\hat{x}[k]$ is the estimation of $x[k]$ that is defined by:

$$
x[k]=\left[\begin{array}{c}
\mathrm{s}[\mathrm{k}] \\
q[k]
\end{array}\right]=\left[\begin{array}{l}
V_{G} \sqrt{2} \sin \left(\omega k T_{s}\right) \\
V_{G} \sqrt{2} \cos \left(\omega k T_{s}\right)
\end{array}\right],
$$

and $A$ is the state transition matrix defined by:

$$
A=\left(\begin{array}{cc}
\cos \left(\omega T_{s}\right) & \sin \left(\omega T_{s}\right) \\
-\sin \left(\omega T_{s}\right) & \cos \left(\omega T_{s}\right)
\end{array}\right) .
$$

The estimation of the covariance matrix is defined by:

$$
\hat{P}[k]=A P[k-1] A^{T}+Q,
$$

where, $Q$ is the covariance matrix. The optimal Kalman gains are obtained with the matrix:

$$
K_{G}[k]=\hat{P}[k] H^{T}\left(H \hat{P}[k] H^{T}+R\right)^{-1},
$$

where, $\hat{P}[k]$ is the estimation of the covariance, $\mathrm{R}$ is represented by a scalar, and $H$ is defined as:

$$
H=\left[\begin{array}{ll}
1 & 0
\end{array}\right] \text {. }
$$

With the previous set of equations the state estimation can be updated through:

$$
\hat{x}[k]=\hat{x}[k-1]+K_{G}\left(v_{g}-H \hat{x}[k-1]\right) .
$$


(a)

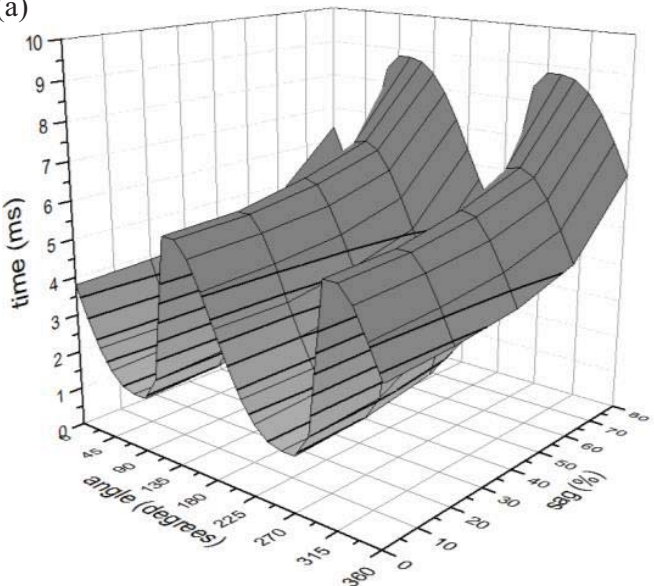

(b)

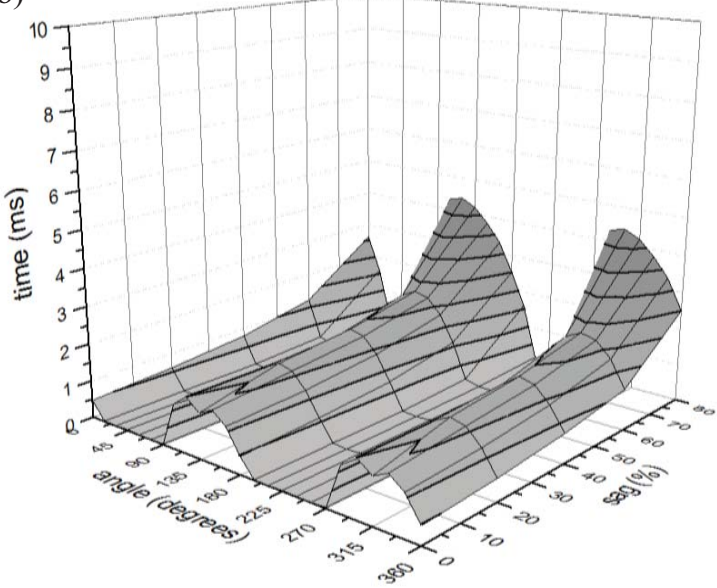

Fig. 4. Simulations results considering the voltage sag depth (sag (\%)), the voltage angle where is identified the sag (angle (degrees)), and the time required to detect when the rms value of the voltage is below $85 \%$ (time (ms)): (a) Rms value calculation method; (b) Rms value estimation using a Kalman filter.

Finally, the estimation of the power grid voltage rms value is given by:

$$
\widehat{V_{G}}=\frac{\sqrt{\hat{s}[k]^{2}+\hat{q}[k]^{2}}}{\sqrt{2}} .
$$

In the scope of this paper is assumed that a power outage occurs when the voltage rms value decreases below $85 \%$ of its nominal value. This threshold is in accordance with standard EN 50160. Henceforward, this value will be used as a reference to the analysis presented in this paper. The aforementioned two methods (rms value calculation and estimation) were compared through simulations results in order to assess the performance of both methods. Fig. 4 shows a comparison of both methods based on simulations results. In this comparison, the voltage sag depth (\%), the voltage angle (degrees) where the sag is identified and the time (ms) required to detect when the rms value of the voltage is below $85 \%$ were considered. Considering the obtained results shown in Fig. 4 and bearing in mind that the on-board EV battery charger must have a small transfer time from the $\mathrm{G} 2 \mathrm{~V}$ to the $\mathrm{iV} 2 \mathrm{H}$ operation mode, the Kalman filter method to estimate the power grid rms voltage is the most suitable for faster detection of the power outages in most of the situations. Hereinafter, the Kalman filter method is used to obtain the experimental results. It is important to note that the digital implementation of the Kalman filter method is

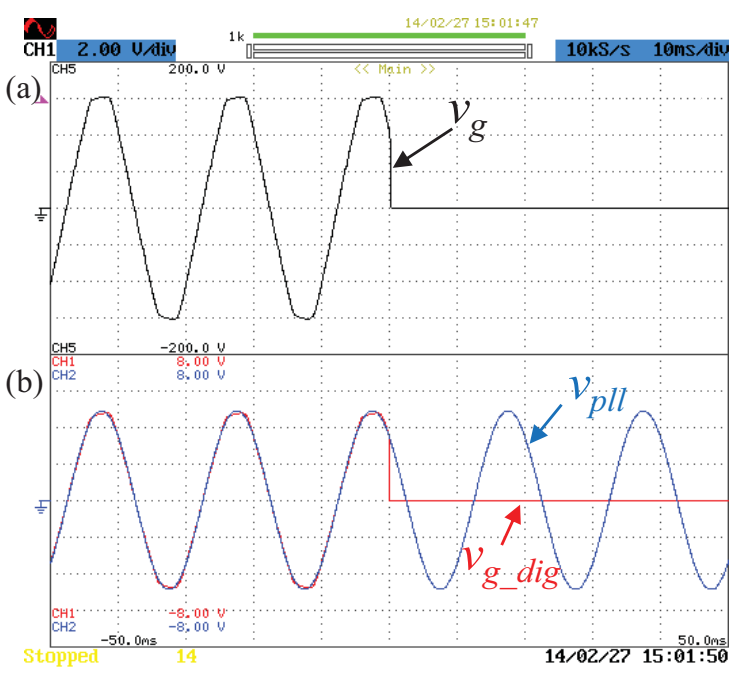

Fig. 5. Detection of a power outage: (a) Analog signal of the power grid voltage $\left(v_{g}\right)(50 \mathrm{~V} /$ div $)$; (b) Digital signal of the power grid voltage $\left(v_{g} \operatorname{dig}\right)$ and the pll signal.

more complex and requires more memory resources than the traditional rms calculation. In the scope of this paper, using a sampling period of $25 \mu \mathrm{s}$, the calculus of Kalman filter method requires $4.4 \mu \mathrm{s}$ and the calculus of traditional $\mathrm{rms}$ requires $0.8 \mu \mathrm{s}$.

\section{Synchronization with the Power Grid Voltage}

In order to implement the $\mathrm{G} 2 \mathrm{~V}$ and $\mathrm{V} 2 \mathrm{G}$ operation modes, the on-board EV battery charger current reference must be synchronized with the fundamental component of the power grid voltage. This synchronization is achieved using an algorithm of a single-phase phase-locked loop (PLL). In the scope of this paper the enhanced PLL proposed in [26] is used.

\section{1) Power Outage}

As aforesaid, in the G2V and V2G operation modes the PLL is synchronized with the fundamental component of the power grid voltage. When the rms value of the power grid voltage falls below $85 \%$ of its nominal value it is considered that a power outage occurs. In those situations, the switch $s w$ (c.f., Fig. 6) is opened to isolate the home from the power grid, and the phase-error of the PLL algorithm is forced to be zero, so that the output signal of the PLL will be a sinusoidal signal with a frequency of $50 \mathrm{~Hz}$. This output signal is used to obtain the voltage reference to the ac-dc converter. Fig. 5 shows the experimental results of a situation when a power outage occurs. As it can be seen, the $v_{\text {pll }}$ signal is maintained with the same amplitude and frequency. In this figure the analog signal of the power grid voltage is represented, as well as its digital signal in comparison with the $v_{\text {pll }}$ signal.

\section{2) Voltage Restoration}

During a power outage, the PLL output signal maintains the same frequency and amplitude that it had before the power outage (the phase-error is forced to be zero). When the power grid voltage is restored, the digital control system detects such a situation in the same way that it detects when a power outage occurs, i.e., the estimated rms value is above the threshold of $85 \%$. In such case, the digital control system acts to resynchronize the $v_{\text {pll }}$ signal with the power grid voltage. To perform this task, the phase-error of the PLL algorithm is no longer forced to zero, so that the PLL starts the resynchronization with the power grid voltage. The 


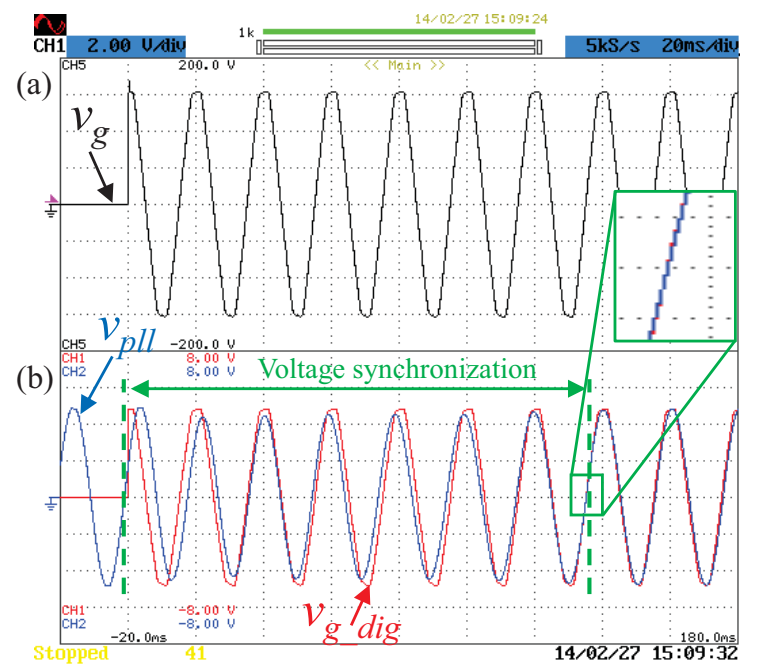

Fig. 6. Detection of power grid voltage restoration and resynchronization: (a) Analog signal of the power grid voltage $\left(v_{g}\right)(50 \mathrm{~V} / \mathrm{div})$; (b) Digital signal of the power grid voltage $\left(v_{g_{-}}\right.$dig $)$and the $p l l$ signal.

resynchronization process is considered complete after the necessary delay of $120 \mathrm{~ms}$ to minimize the phase-error. When it occurs, the switch $s w$ is closed, the on-board EV battery charger stops the operation as voltage-source in the same instant, and the home electrical appliances are again connected to the power grid. Fig. 6 shows the experimental results of a situation when a voltage restoration and a resynchronization occurs. As it can be seen, before the voltage restoration, the $v_{\text {pll }}$ signal has a phase and an amplitude (as previously explained), and the digital signal of the power grid voltage is zero. When the power grid voltage is restored, the $v_{\text {pll }}$ signal completes the synchronization with the fundamental component of the power grid voltages after $120 \mathrm{~ms}$.

\section{ON-BOARD EV BATTERY CHARGER: Current AND Voltage CONTROL Algorithms}

In order to evaluate the $\mathrm{iV} 2 \mathrm{H}$ operation mode the on-board EV battery charger presented in Fig. 7 was used. As it can be seen in Fig. 7(a), this EV battery charger is composed of an ac-dc converter and a dc-dc converter. In order to comply with the proposed operation mode, the EV battery charger must provide a command signal to the main switch, identified in Fig. 7 as $s w$. It is important to note that the iV2H operation mode can be implemented on on-board (typically with nominal power below $3.5 \mathrm{~kW}$ ) or off-board systems (typically with nominal power above $20 \mathrm{~kW}$ ) [27]. Because off-board EV battery chargers are used to charge batteries as fast as possible, and usually are not installed in homes, this paper relates only to on-board battery chargers. However, it is important to emphasize that the control algorithm of the proposed $\mathrm{iV} 2 \mathrm{H}$ operation mode can be adapted to be used in off-board EV battery chargers. For such purpose it is necessary to use a three-phase PLL with a Kalman filter for each phase. The aim of using the iV2H operation mode is associated with the benefits for the smart grids and smart homes.

\section{A. Grid-to-Vehicle (G2V) and Vehicle-to-Grid (V2G)}

During the G2V and $\mathrm{V} 2 \mathrm{G}$ operation modes, the ac-dc converter operates with sinusoidal current and unitary power factor on the ac side and regulates the dc-link voltage. The ac current reference in discrete time, at each instant $k$, is expressed as:
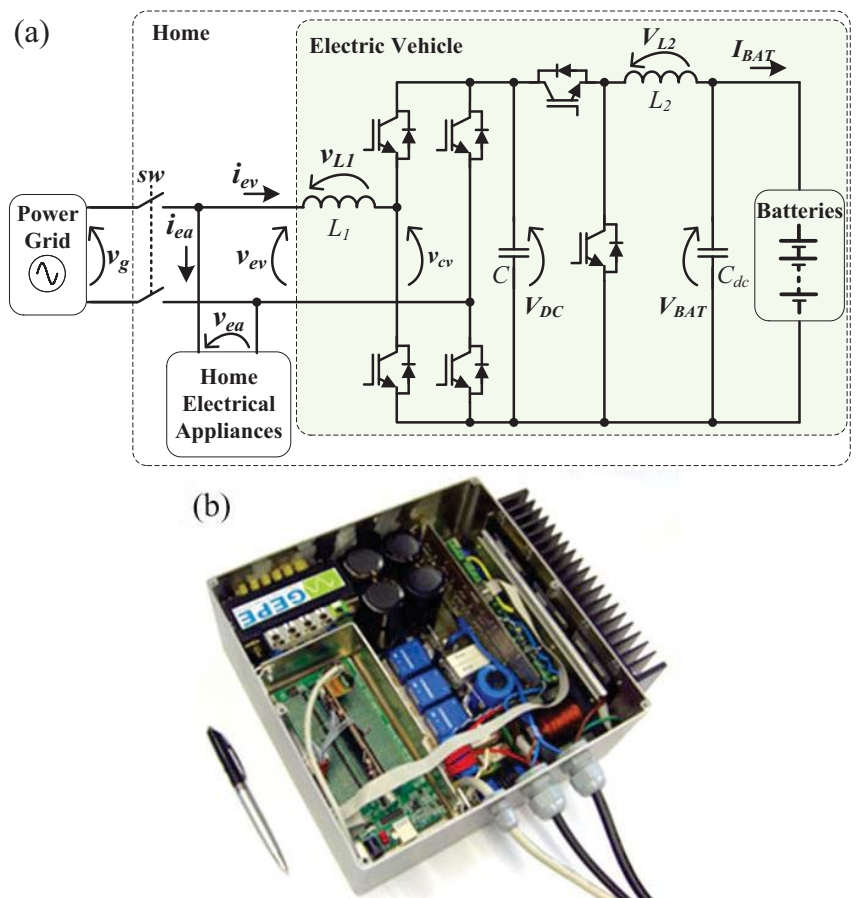

Fig. 7. EV battery charger used to validate the proposed iV2H operation mode: (a) Topology of the EV battery charger; (b) Hardware of the EV battery charger.

$$
i_{e v}{ }^{*}[\mathrm{k}]=\frac{P_{D C}{ }^{*}[k]+I_{B A T}[k] V_{B A T}[k]}{V_{G}[k]^{2}} v_{g}[k],
$$

where, $P_{D C}{ }^{*}[k]$ is the reference power obtained from a PI controller to regulate the dc-link voltage, $V_{G}[k]$ is the rms value of the power grid voltage, $v_{g}[k]$ is the instantaneous value of the power grid voltage, and $I_{B A T}[k]$ and $V_{B A T}[k]$ are the current and voltage in the batteries, respectively. It is important to note that the current $I_{B A T}[k]$ is positive or negative according to the G2V or V2G operation modes, which results in a positive or negative current reference $\left(i_{e v}{ }^{*}\right)$. With the current reference $\left(i_{e v} *[k]\right)$, the ac current is controlled by:

$$
\begin{gathered}
v_{C V}[k]=v_{g}[k]-\frac{L_{1}}{T}\left(2 i_{e v}{ }^{*}[k]-i_{e v}{ }^{*}[k-1]\right. \\
\left.-i_{e v}[k]-i_{\text {ev error }}[k-1]\right),
\end{gathered}
$$

where, $k$ denotes the actual sampling and $k-1$ indicates the previous sampling. The voltage reference that the ac-dc converter must produce $\left(v_{c v}[k]\right)$ is compared to a $20 \mathrm{kHz}$ triangular center aligned carrier, to obtain the gate pulse patterns. A strategy to avoid dead-time effects was used, and it consists in adding a digital value to the voltage reference $\left(v_{c v}[k]\right)$ during the positive semi-cycle, and subtracting the same value during the negative semi-cycle. This value is calculated according to the amplitude of the carrier and the delay of the dead-time.

On the dc side, the voltage that the dc-dc converter must produce $\left(v_{\text {buck }}[k]\right)$ in order to charge the batteries with constant current is defined by:

$$
v_{\text {buck }}[k]=V_{B A T}[k]+\frac{L_{2}}{T}\left(I_{B A T}{ }^{*}[k]-I_{B A T}[k]\right) .
$$

As aforementioned, during the $\mathrm{V} 2 \mathrm{G}$ operation mode, the ac-dc converter regulates the dc-link voltage and the ac current reference is the function of the batteries discharging current. 
Therefore, the dc-dc converter operates as a boost converter and the voltage reference $\left(v_{\text {boost }}[k]\right)$ that allows discharging the batteries with the required current is defined by:

$$
v_{\text {boost }}[k]=V_{B A T}[k]-\frac{L_{2}}{T}\left(I_{B A T}{ }^{*}[k]-I_{B A T}[k]\right) .
$$

\section{B. Improved Vehicle-to-Home (iV2H)}

During the iV2H operation mode, the ac-dc converter is used to synthetize the required voltage to apply to the electrical appliances. The voltage that the converter must produce is obtained directly from the comparison of the voltage reference $\left(v_{g}{ }^{*}\right)$ and the triangular carrier. In this operation mode the same strategy is also used to avoid the dead-time effect in the produced voltage. In this operation mode the dc-dc converter, which operates as a boost converter, is used to regulate the dc-link voltage. This voltage is controlled by adjusting the duty-cycle value of the PWM modulator, i.e., the reference of the voltage is directly compared to the carrier in order to obtain the gate pulse patterns. The duty-cycle in each instant $k$ is expressed according to the battery voltage and the dc-link voltage reference by:

$$
\delta_{C O N V}[k]=1-\frac{V_{B A T}[k]}{V_{D C}{ }^{*}[k]} .
$$

\section{IV. iV2H OPERATION MODE: EXPERIMENTAL RESUltS}

The experimental setup used to validate the proposed $\mathrm{iV} 2 \mathrm{H}$ operation mode (i.e., the EV battery charger operation as an off-line UPS) is shown in Fig. 8. This figure shows the EV bidirectional battery charger and the EV batteries. Fig. 9 shows the load emulating the electrical appliances used in the experimental setup. The specifications of the on-board EV battery charger and the key components are shown, respectively, in Table I and Table II. Although the nominal input ac voltage of the on-board EV battery charger is $230 \mathrm{~V}$, the experimental results were obtained with a voltage of $115 \mathrm{~V}$. It is important to note that this operating voltage does not invalidate the experimental results and the verification of the proposed $\mathrm{iV} 2 \mathrm{H}$ operation mode. In the future, the on-board EV battery charger will be integrated in our EV (CEPIUM) [28] and will operate at $230 \mathrm{~V}$ input ac voltage. The battery pack is composed by a set of 12 sealed absorbed glass mat (AGM) batteries, which are part of our EV CEPIUM. This EV was developed by our research group and, nowadays, is under tests of new concepts and motor drive controls. The EV bidirectional battery charger is part of this EV [28], and is also used in laboratory to validate new operation modes, as the proposed in this paper. The home electrical appliances are composed by incandescent lamps (i.e., resistive electrical appliances) and by computers and TVs (i.e., typical nonlinear electrical appliances composed by diode bridge rectifiers with input inductive filter and output capacitive filter). The experimental results were acquired with a Yokogawa DL708E digital oscilloscope.

\section{A. Steady State Operation}

In this item the experimental results obtained in steady state during the $\mathrm{G} 2 \mathrm{~V}$ and $\mathrm{V} 2 \mathrm{G}$ operation modes are presented. Specifically, Fig. 10(a) shows the power grid voltage $\left(v_{g}\right)$ and the on-board EV battery charger current $\left(i_{e v}\right)$ during the G2V operation mode, and Fig. 10(b) shows the same variables during the V2G operation mode. These results were obtained in

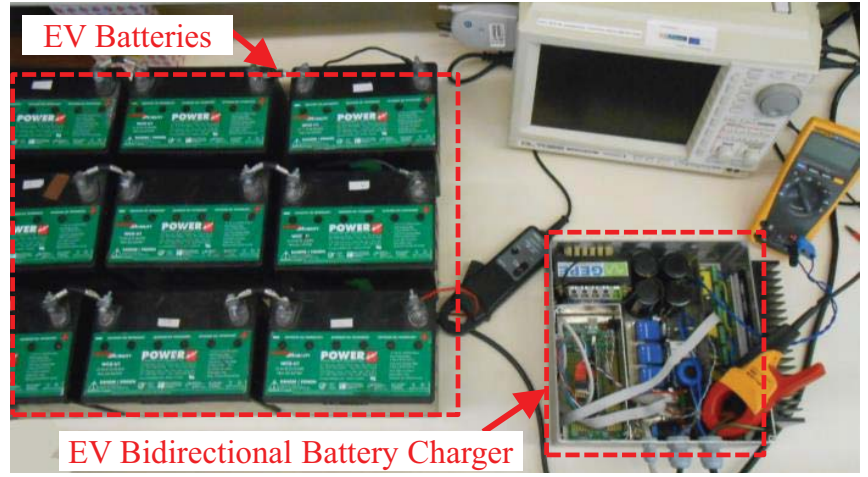

Fig. 8. Experimental setup used to validate the proposed iV2H operation mode (EV battery charger operation as off-line UPS).

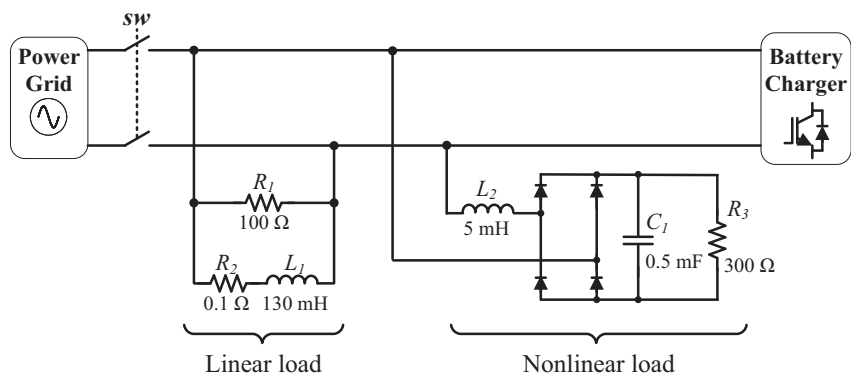

Fig. 9. Loads emulating electrical appliances used in the experimental setup.

TABLE I

SPECIFICATIONS OF THE ON-BOARD EV BATTERY CHARGER

\begin{tabular}{lcc}
\hline \hline \multicolumn{1}{c}{ Parameters } & Value & Unit \\
\hline Input ac Voltage (rms) & 230 & $\mathrm{~V}$ \\
Maximum Input ac Current (rms) & 15 & $\mathrm{~A}$ \\
Input ac Maximum Current Ripple & 0.5 & $\mathrm{~A}$ \\
Maximum Input Power & 3.5 & $\mathrm{~kW}$ \\
Output DC Voltage Range & 100 to 300 & $\mathrm{~V}$ \\
Maximum Output DC Current & 10 & $\mathrm{~A}$ \\
Battery Pack Nominal Voltage & 144 & $\mathrm{~V}$ \\
Prototype Weight & 4.9 & $\mathrm{~kg}$ \\
Prototype Dimensions & $250 \times 290 \times 95$ & $\mathrm{~mm}$ \\
\hline \hline
\end{tabular}

TABLE II

KEY COMPONENTS OF THE ON-BOARD EV BATTERY CHARGER

\begin{tabular}{lcc}
\hline \multicolumn{1}{c}{ Device } & Part / Value & No $^{\circ}$ of Devices \\
\hline DSP & TMS320F28335 & 1 \\
IGBT & FGA25N120ANTD & 6 \\
Inductor $L_{1}$ & $5 \mathrm{mH}$ & 1 \\
Capacitor $C$ & $820 \mu \mathrm{F}$ & 4 \\
Inductor $L_{2}$ & $300 \mu \mathrm{H}$ & 1 \\
Capacitor $C_{d c}$ & $680 \mu \mathrm{F}$ & 1 \\
\hline \hline
\end{tabular}

a detail of $50 \mathrm{~ms}$ aiming at illustrating that the current is sinusoidal and in phase (or phase opposition) with the power grid voltage. It is important to note that although the power grid voltage is little distorted (due to other nonlinear electrical appliances), the current waveform is sinusoidal, contributing to preserve the power quality of the electrical grid. The measured total harmonic distortion (THD) of the power grid voltage is $3.8 \%$ and the THD of the EV battery charger current is $1.4 \%$.

\section{B. Transient Response: Power Outage}

In this section some experimental results in transient response when a power outage occurs are presented. For such purpose, the Kalman filter was used to estimate the rms value 

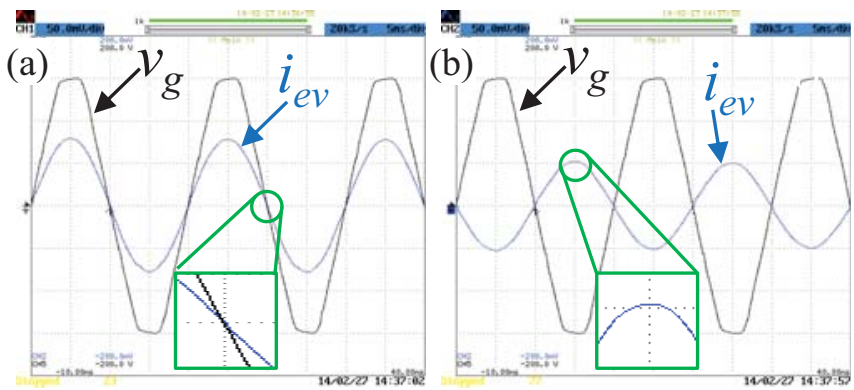

Fig. 10. Experimental results of the power grid voltage $\left(v_{g}\right)(50 \mathrm{~V} /$ div) and the on-board EV battery charger main current $\left(i_{e v}\right)(5 \mathrm{~A} / \mathrm{div})$ : (a) During the G2V operation mode; (b) During the V2G operation mode.

of the power grid voltage, and consequently to detect when the rms value falls below $85 \%$ of its nominal value. These results were obtained aiming at illustrating the proposed operation mode in two distinct situations, namely, when the EV is plugged in at home but not charging the batteries, and when the $\mathrm{EV}$ is plugged in and during the batteries charging process (G2V operation mode).

\section{1) EV Plugged In but not Charging the Batteries}

In the first case, is considered that the EV is plugged in at home, but it is not charging the batteries, when a power outage occurs. The experimental results for this situation are shown in Fig. 11. This figure shows the voltage $\left(v_{e a}\right)$ and the current $\left(i_{e a}\right)$ in the electrical appliances and the current in the on-board EV battery charger $\left(i_{e v}\right)$. As it can be seen, to detect when the rms value decreases below $85 \%$ of its nominal value, only $0.2 \mathrm{~ms}$ were required, i.e., the transfer time is very low. In this situation, after the power outage, the switch $s w$ is opened and the on-board EV battery charger changes the control algorithm to the $\mathrm{iV} 2 \mathrm{H}$ operation mode.

It is important to refer that the voltage produced by the converter has a little distortion due to the output filter of the on-board EV battery charger. As a consequence of this voltage distortion, the current is also different. This situation can be easily solved using distinct line filters: one for the G2V and V2G operation modes and other one for the $\mathrm{iV} 2 \mathrm{H}$ operation mode. Nevertheless, using two distinct line filters will increase the size and weight of the on-board EV battery charger. Thus, taking into account that the main function of the EV battery charger is the $\mathrm{G} 2 \mathrm{~V}$ operation mode, it is not advantageous to use another line filter.

Table III shows the measured THD of the voltage and current of the electrical appliances, before and after the power outage, and considering linear and nonlinear electrical appliances. As it can be seen, using a linear electrical appliance, the THD of the voltage applied to the electrical appliance is reduced from $3.8 \%$ to $2.2 \%$ after the power outage. In this case, the THD of the current is the same of the voltage. On the other hand, using a nonlinear electrical appliance, the THD of the voltage increases from $3.8 \%$ to $7.8 \%$ after the power outage and consequently the THD of the current also increases (from $24.1 \%$ to $31.0 \%$ ). The THD of the voltage applied to the nonlinear electrical appliances after the power outage is a little bit higher $(7.8 \%)$ when compared to the THD before the power outage $(3.8 \%)$. Nevertheless, it is an acceptable value for this type of situation and it is preferable than a power outage [29]. Moreover, this maximum value

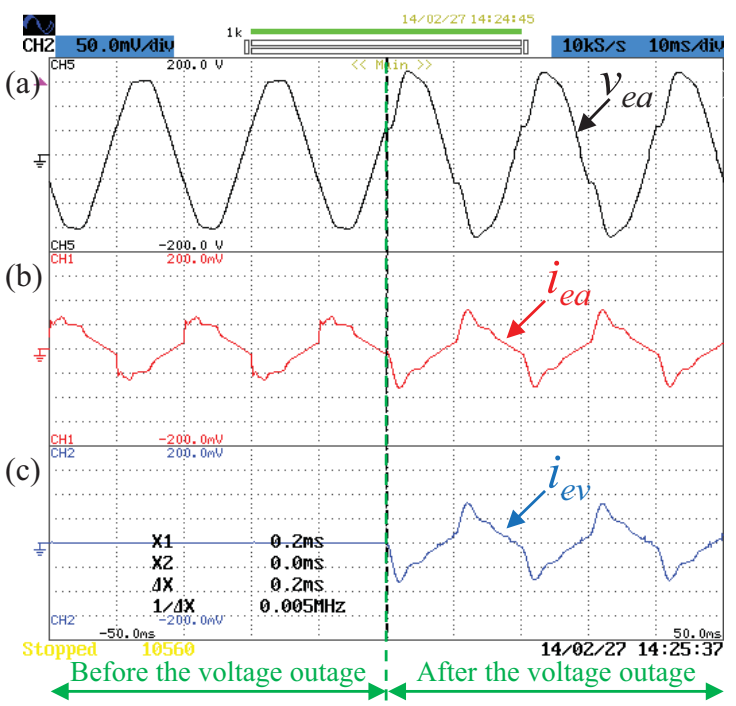

Fig. 11. Experimental results of a power outage detection when the EV is plugged in but not charging the batteries: (a) Voltage in the electrical appliances $\left(v_{e a}\right)(50 \mathrm{~V} / \mathrm{div})$; (b) Current in the electrical appliances $\left(i_{e a}\right)$ $(5 \mathrm{~A} / \mathrm{div})$; (c) Current in the on-board EV battery charger $\left(i_{e v}\right)(5 \mathrm{~A} / \mathrm{div})$.

TABLE III

THD OF THE VOLTAGE AND CURRENT OF THE ELECTRICAL APPLIANCES

\begin{tabular}{c|c|c|c}
\hline \multicolumn{2}{c|}{$\begin{array}{c}\text { Electrical } \\
\text { Appliance }\end{array}$} & $\begin{array}{c}\text { Before the } \\
\text { Power Outage }\end{array}$ & $\begin{array}{c}\text { After the Power } \\
\text { Outage }\end{array}$ \\
\hline \multirow{3}{*}{ Linear } & $v_{e a}$ & $3.8 \%$ & $2.2 \%$ \\
& $i_{e a}$ & $3.8 \%$ & $2.2 \%$ \\
\hline \multirow{2}{*}{ Nonlinear } & $v_{e a}$ & $3.8 \%$ & $7.8 \%$ \\
& $i_{e a}$ & $24.1 \%$ & $31.0 \%$ \\
\hline \hline
\end{tabular}

$(7.8 \%)$ is below the limit of $8 \%$ established by the standard EN $50160[30]$.

\section{2) EV Plugged In and Charging the Batteries}

In the second case is considered that the EV is plugged in at home (performing the battery charging process) and a power outage occurs. The experimental results of this situation are shown in Fig. 12. In this figure the voltage in the electrical appliances $\left(v_{e a}\right)$, the current in the electrical appliances $\left(i_{e a}\right)$, and the current in the on-board EV battery charger $\left(i_{e v}\right)$ are shown. Also in this case, $0.2 \mathrm{~ms}$ were required to detect that the rms value decreases below $85 \%$ of its nominal value. In this situation, the EV is performing the battery charging process and after the power outage, the switch $s w$ is opened and the on-board EV battery charger changes the control algorithm to the $\mathrm{iV} 2 \mathrm{H}$ operation mode. Also in this case, the produced voltage by the on-board EV battery charger has a little distortion due to the reasons explained before.

\section{Transient Response: Voltage Restoration}

In this section some experimental results in transient response during the power grid voltage restoration are presented. When the voltage restoration is detected, the transition from the $\mathrm{iV} 2 \mathrm{H}$ operation mode to the steady state operation does not occur realized immediately. Before the transition, a time delay is used for a complete synchronization of the PLL with the power grid voltage. Fig. 13 shows a situation of a voltage restoration, i.e., the PLL resynchronization with the power grid voltage and the transition from the iV2H operation mode to the steady state 


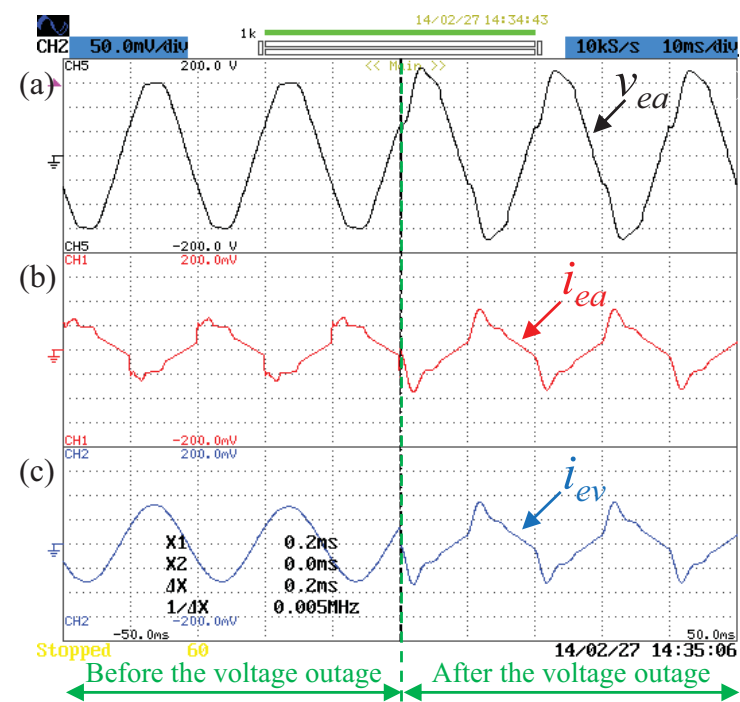

Fig. 12. Experimental results of a power outage detection when the EV is plugged in and charging the batteries: (a) Voltage in the electrical appliances $\left(v_{e a}\right)(50 \mathrm{~V} / \mathrm{div})$; (b) Current in the electrical appliances $\left(i_{e a}\right)(5 \mathrm{~A} / \mathrm{div}) ;(\mathrm{c})$ Current in the on-board EV battery charger $\left(i_{e v}\right)(5 \mathrm{~A} / \mathrm{div})$.

operation. In this figure the voltage applied to the electrical appliances $\left(v_{e a}\right)$ is shown, as well as the digital signals of the PLL and power grid voltage. After the PLL resynchronization with the power grid voltage, the electrical appliances are connected again to the power grid, i.e., the switch $s w$ is closed and the on-board EV battery charger returns to its normal operation. As presented before, a power outage can occur during the $\mathrm{G} 2 \mathrm{~V}$ operation mode. In this situation, the on-board EV battery charger stops its normal operation and changes the control algorithm to the iV2H operation mode. When the voltage is restored, and after the required delay to the resynchronization, the on-board EV battery charger returns to its normal operation, i.e., the G2V operation mode (battery charging process). Fig. 14 shows the experimental results when the electrical appliances are connected again to the power grid. As it can be seen, no transient phenomenon was observed when the switch $s w$ (c.f. Fig. 7) is on again. Once there are no restrictions to start the battery charging process (the time required to perform the full battery charging process is higher than the time in the iV2H operation mode), this task can be performed carefully, in order to avoid possible relapses of power outages. This situation is illustrated in Fig. 15, where about $100 \mathrm{~ms}$ were required.

\section{CONCLUSION}

This paper presents a study that was conducted in order to assess the electric vehicle (EV) operation as an off-line uninterruptible power supply (UPS). For such purpose, an on-board EV battery charger controlled in the grid-to-vehicle $(\mathrm{G} 2 \mathrm{~V})$, in the vehicle-to-grid (V2G) and in the improved vehicle-to-home $(\mathrm{iV} 2 \mathrm{H})$ operation modes was used. Using the limit of $85 \%$ of the nominal power grid rms voltage value $(0.85$ $\mathrm{x} 115 \mathrm{~V})$ to indicate a power outage, two algorithms to detect this situation are compared: the rms value calculation based on half cycle of the power grid voltage, and the rms value estimation based on a Kalman filter. The iV2H operation mode was experimentally validated in both steady and transient states. Two distinct situations were considered in transient

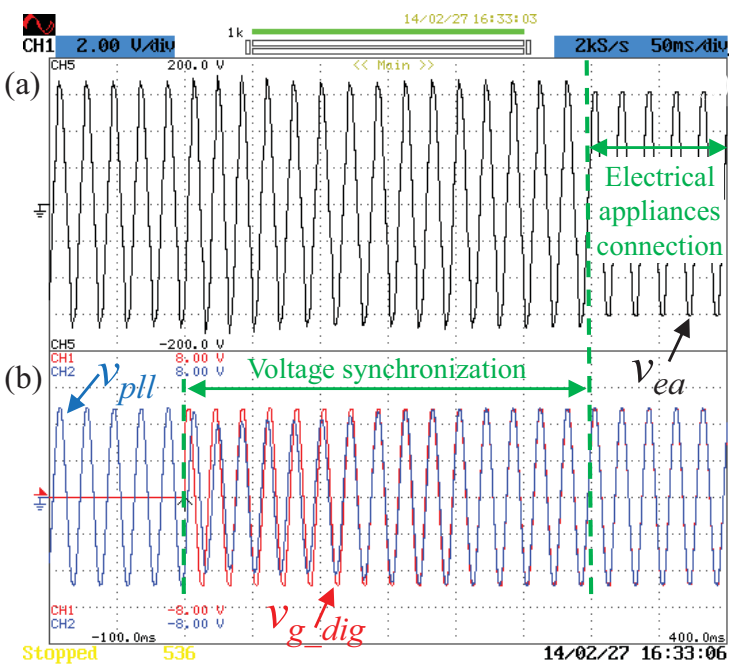

Fig. 13. Experimental results of a voltage restoration ( $p l l$ resynchronization with the power grid voltage and transition from the iV2H operation mode to the steady state operation): (a) Voltage applied to the electrical appliances $\left(v_{e a}\right)(50 \mathrm{~V} / \mathrm{div})$; (b) Digital signals of the pll and the power grid voltage $\left(v_{g \_ \text {dig }}\right)$.

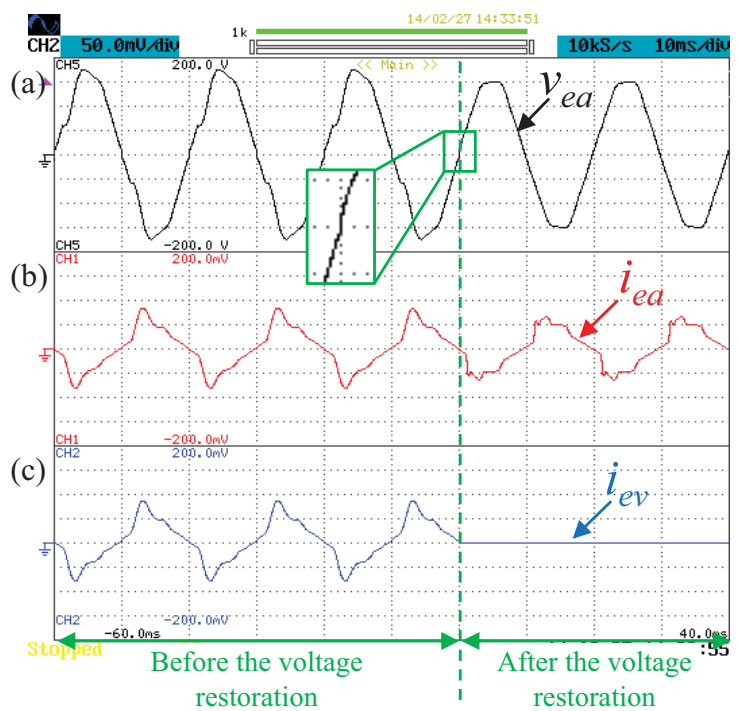

Fig. 14. Experimental results of a power outage restoration: (a) Voltage in the electrical appliances $\left(v_{e a}\right)(50 \mathrm{~V} / \mathrm{div})$; (b) Current in the electrical appliances $\left(i_{e a}\right)(5 \mathrm{~A} / \mathrm{div}) ;$ (c) Current in the on-board EV battery charger $\left(i_{e v}\right)$ (5 A / div).

state, namely, when a power outage occurs with the EV plugged in but not charging the batteries and with the EV plugged in and charging the batteries. Experimental results of the proposed $\mathrm{iV} 2 \mathrm{H}$ operation mode during transient and steady states showing the detection of a power outage and the voltage restoration are presented.

\section{ACKNOWLEDGMENT}

This work has been supported by FCT - Fundação para a Ciência e Tecnologia in the scope of the projects: PEstUID/CEC/00319/2013.

\section{REFERENCES}

[1] Craig H. Stephan, John Sullivan, "Environmental and Energy Implications of Plug-In Hybrid-Electric Vehicles," Environ. Sci. Technol. vol.42, no.4 pp.1185-1190, Jan. 2008. 


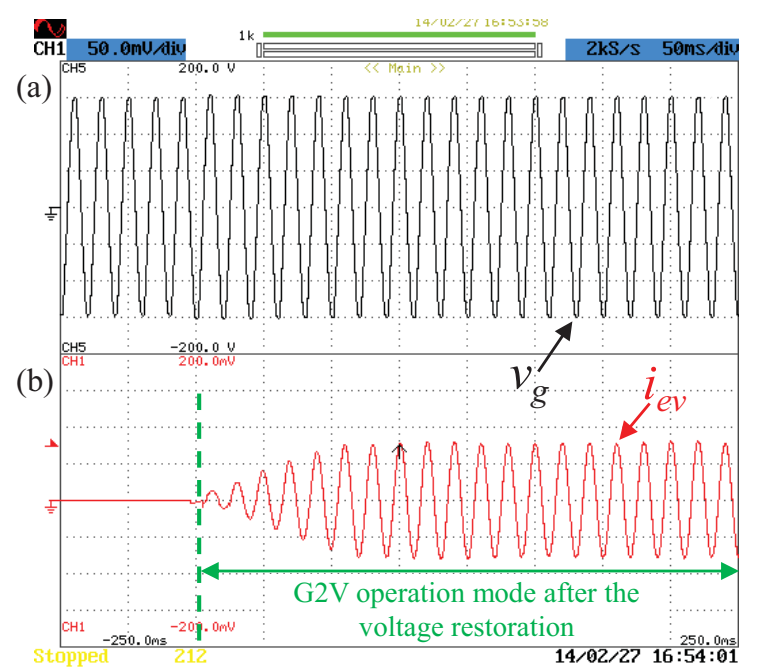

Fig. 15. Experimental results of the beginning of the G2V operation mode after a voltage restoration and resynchronization: (a) Power grid voltage $\left(v_{g}\right)$ $\left(50 \mathrm{~V} /\right.$ div) (b) EV battery charger current $\left(i_{e v}\right)(5 \mathrm{~A} / \mathrm{div})$.

[2] C. C. Chan, "The State of the Art of Electric, Hybrid, and Fuel Cell Vehicles," Proc. IEEE, vol.95, no.4, pp.704-718, Apr. 2007.

[3] Albert G. Boulanger, Andrew C. Chu, Suzanne Maxx, David L. Waltz, "Vehicle Electrification: Status and Issues," Proceedings of the IEEE, vol.99, no.6, pp.1116-1138, June 2011.

[4] Trevor Morgan, "Smart Grids and Electric Vehicles: Made for Each Other?," International Transport Forum, Discussion Paper, Fev. 2012.

[5] Fabian Kennel, Daniel Görges, Steven Liu, "Energy Management for Smart Grids With Electric Vehicles Based on Hierarchical MPC," IEEE Trans. Ind. Informat., vol.9, no.3, pp.1528-1537, Aug. 2013.

[6] Eric Sortomme, Mohammad M. Hindi, S. D. James MacPherson, S. S. Venkata, "Coordinated Charging of Plug-In Hybrid Electric Vehicles to Minimize Distribution System Losses,' IEEE Trans. Smart Grid, vol.2, no.1, pp.186-193, Mar. 2011.

[7] Zhe Yu, Liyan Jia, Mary C. Murphy-Hoye, Annabelle Pratt, and Lang Tong, "Modeling and Stochastic Control for Home Energy Management," IEEE Trans. Smart Grid, vol.4, no.4, pp.2244-2255, Dec. 2013

[8] João A. Peças Lopes, Filipe Soares, Pedro M. Rocha Almeida, "Integration of Electric Vehicles in the Electric Power Systems," Proc. IEEE, vol.99, no.1, pp.168-183, Jan. 2011.

[9] Ahmed Yousuf Saber, Ganesh Kumar Venayagamoorthy, "Plug-in Vehicles and Renewable Energy Sources for Cost and Emission Reductions," IEEE Trans. Ind. Electron., vol.58, no.4, pp.1229-1238, Apr. 2011.

[10] Rui Freire, Joaquim Delgado, João M. Santos, Aníbal T. de Almeida, "Integration of Renewable Energy Generation with EV Charging Strategies to Optimize Grid Load Balancing," IEEE International Conference on Intelligent Transportation Systems, pp.392-396, Sept. 2010 .

[11] Willet Kempton, Victor Udo, Ken Huber, Kevin Komara, Steve Letendre, Scott Baker, Doug Brunner, Nat Pearre, "A test of vehicle-togrid (V2G) for energy storage and frequency regulation in the PJM system," University of Delaware, Nov. 2008.

[12] Vítor Monteiro, J. G. Pinto, Bruno Exposto, João C. Ferreira, Carlos Couto, João L. Afonso, “Assessment of a Battery Charger for Electric Vehicles with Reactive Power Control," IEEE IECON Industrial Electronics Society, Montréal-Canada, pp.5124-5129, Oct. 2012.

[13] Mithat C. Kisacikoglu, Burak Ozpineci, Leon M. Tolbert, Fred Wang, "Single-phase Inverter Design for V2G Reactive Power Compensation," IEEE APEC Applied Power Electronics Conference and Exposition, pp.808-814, Mar. 2011.

[14] J. G. Pinto, Vítor Monteiro, Henrique Gonçalves, Bruno Exposto, Delfim Pedrosa, Carlos Couto, João L. Afonso, "Bidirectional Battery Charger with Grid-to-Vehicle, Vehicle-to-Grid and Vehicle-to-Home
Technologies," IEEE IECON Industrial Electronics Conference, pp.5934-5939, Vienna Austria, Nov. 2013.

[15] David P. Tuttle, Robert L. Fares, Ross Baldick, Michael E. Webber, "Plug-In Vehicle to Home (V2H) Duration and Power Output Capability," IEEE ITEC Transportation Electrification Conference and Expo, pp.1-7, June 2013

[16] Vítor Monteiro, Bruno Exposto, J. G. Pinto, Raul Almeida, João C. Ferreira, Andrés A. Nogueiras Meléndez, João L. Afonso, "On-Board Electric Vehicle Battery Charger with Enhanced V2H Operation Mode", IEEE IECON Industrial Electronics Conference, pp.1636-1642, Dallas Texas USA, Oct. 2014.

[17] Chunhua Liu, K. T. Chau, Diyun Wu, Shuang Gao, "Opportunities and Challenges of Vehicle-to-Home, Vehicle-to-Vehicle, and Vehicle-toGrid Technologies," Proc. IEEE, vol.101, no.11, pp.2409-2427, Nov. 2013

[18] Vehbi C. Gungor, Dilan Sahin, Taskin Kocak, Salih Ergut, Concettina Buccella, Carlo Cecati, Gerhard P. Hancke, "Smart Grid and Smart Homes - Key Players and Pilot Projects," IEEE Ind. Electron. Mag., vol.6, pp.18-34, Dec. 2012.

[19] Marc Multin, Florian Allerding, Hartmut Schmeck, "Integration of Electric Vehicles in Smart Homes - An ICT-based Solution for V2G Scenarios," IEEE PES ISGT Innovative Smart Grid Technologies, pp.1-8, Jan. 2012.

[20] Duong Tung Nguyen, Long Bao Le, "Joint Optimization of Electric Vehicle and Home Energy Scheduling Considering User Comfort Preference," IEEE Trans. Smart Grid, vol.5, no.1, pp.188-199, Jan. 2014.

[21] Mosaddek Hossain Kamal Tushar, Chadi Assi, Martin Maier, Mohammad Faisal Uddin, "Smart Microgrids: Optimal Joint Scheduling for Electric Vehicles and Home Appliances," IEEE Trans. Smart Grid, vol.5, no.1, pp.239-250, Jan. 2014.

[22] Green Car Congress, "Nissan to launch the 'LEAF to Home' V2H power supply system with Nichicon 'EV Power Station' in June." [Online] Available: 30-05-2012 http://www.greencarcongress.com/2012/05/leafvsh- 20120530.html.

[23] Nikki Gordon-Bloomfield, "Nissan, Mitsubishi, Toyota Turn Electric Cars Into Backup Batteries." (mar. 2014) [online] http://www.greencarreports.com/news/1063565_nissan-mitsubishitoyota-turn-electric-cars-into-backup-batteries

[24] Kristien Clement-Nyns, Edwin Haesen, Johan Driesen, "The Impact of Charging Plug-In Hybrid Electric Vehicles on a Residential Distribution Grid," IEEE Trans. Power Syst., vol.25. no.1, pp.371-380, Feb. 2010.

[25] Mario González, Víctor Cárdenas, "The Kalman Filter in Power Quality - Theory and Applications," InTech, Vedran Kordic (Ed.), Mar. 2010.

[26] M. Karimi-Ghartemani, M. R. Iravani, "A nonlinear adaptive filter for online signal analysis in power systems: applications," IEEE Trans. Power Del., vol.17, no.2, pp.617-622, Apr. 2002.

[27] Alireza Khaligh, Serkan Dusmez, "Comprehensive Topological Analysis of Conductive and Inductive Charging Solutions for Plug-In Electric Vehicles," IEEE Trans. Veh. Technol., vol.61, no.8, pp.34753489, Oct. 2012

[28] Delfim Pedrosa, Vítor Monteiro, Henrique Gonçalves, Júlio S. Martins, João L. Afonso, "A Case Study on the Conversion of an Internal Combustion Engine Vehicle into an Electric Vehicle," IEEE VPPC Vehicle Power and Propulsion Conference, pp.1-5, Oct. 2014.

[29] Bunyamin Tamyurek, "A High-Performance SPWM Controller for Three-Phase UPS Systems Operating Under Highly Nonlinear Loads," IEEE Trans. Power Electron., vol.28., no.8, pp.3689-3701, Aug. 2013.

[30] Leonardo Power Quality Initiative, "Power Quality Application Guide Voltage Disturbances Standard EN 50160," July 2004. 


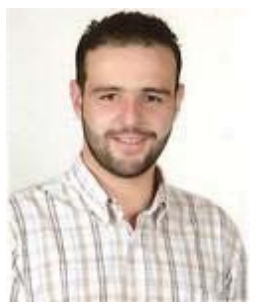

Vítor Monteiro (S'10) was born in Guimarães, Portugal, on May 1984. He received the M.Sc. in Industrial Electronics and Computers Engineering, from the School of Engineering of the University of Minho, in 2012. Since 2008 he is a member of the Group of Energy and Power Electronics (GEPE) of the Centro Algoritmi, at the University of Minho. Currently he is a $\mathrm{PhD}$ student supported by the doctoral scholarship SFRH/BD/80155/2011 granted by the Portuguese FCT agency, and a collaborator of the Centro Algoritmi of the University of Minho. His research interests are related with Power Electronics Converters, Digital Control Techniques, Smart Grids, and Electric Vehicles.

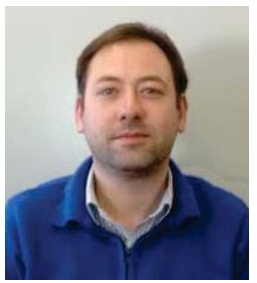

Bruno Exposto (S'10) was born in Valença, Portugal on July, 1982. He received the M.Sc. in Industrial Electronics and Computers Engineering, from the School of Engineering of the University of Minho, in 2010. After that he was a Researcher Fellow in project UPQC-IM-REI (Unified Power Quality Conditioner with Integrated Monitoring and Renewable Energy Interface (PTDC/EEAEEL/104569/2008 - PTDC/2008)) at University of Minho, Portugal. Currently is a $\mathrm{PhD}$ student supported by the doctoral scholarship SFRH/BD/87999/2012 granted by the Portuguese FCT agency, and a collaborator of the Centro Algoritmi of University of Minho. His research activities are related with power quality, power quality conditioners, power electronics and control systems. Also he participates in several power quality studies in industrial environment. Bruno is a student member of IEEE, Industrial Electronics Society and Power Electronics Society.

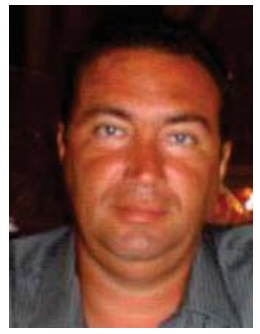

João C. Ferreira (M'01) is Professor at the Polytechnic Institute of Lisbon (IPL/ISEL) and Consultant with different companies and institutions. He graduated in Physics at the Technical University of Lisbon (UTL/IST), Portugal, received an MSC in Telecommunication and a PhD degree in Computer Science Engineering from UTL/IST. His professional and research interests are in retrieval, geographic and multimedia retrieval, Electric Vehicle, Intelligent Systems, intelligent transportation (ITS) and sustainable mobility systems. He is the author of over 140 scientific papers of international conferences and workshops in different areas of computer science.

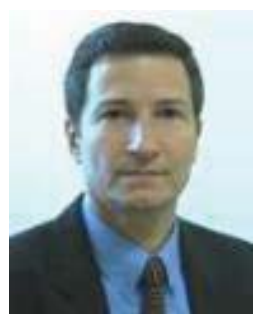

João Luiz Afonso (M'00) was born in Rio de Janeiro, Brazil, in 1963. He received the B.S. and M.Sc. degrees in Electrical Engineering from the Federal University of Rio de Janeiro in 1986 and 1991, respectively, and the Ph.D. degree in Industrial Electronics from the University of Minho, Guimarães, Portugal, in 2000. Since 1993, he has been with the Department of Industrial Electronics,

University of Minho, where he is Associate Professor. He teaches Electrical Machines, Electrical Energy Systems, Complements of Power Electronics, Electrical Power Quality, Active Power Filters and Renewable Energy. He is a researcher with the Group of Energy and Power Electronics (GEPE), and he coordinates the thematic strand of Sustainable and Smart Cities of the Centro Algoritmi. His research interests include: Power Quality, Active Power Filters, Renewable Energy, Electric Vehicles, Energy Efficiency, Energy Storage Systems, Innovative Railway Systems, Smart Grids and Smart Cities. 